\title{
Neck Dissection for Adenoid Cystic Carcinoma
}

\author{
Michael F. Gensheimer, MD \\ Department of Radiation Oncology, Stanford University, Stanford, CA
}

\section{Dear Editor,}

I would like to raise an issue with the paper by Amit et al. published in Annals of Surgical Oncology. ${ }^{1}$ While the paper was published several years ago, it is still very relevant as it remains the largest series to report on outcomes of elective neck dissection (END) for adenoid cystic carcinoma. My concern is that for several anatomic subsites, readers could think that the rate of node positivity is much higher than it actually is. Quoting from the abstract: "The overall rate of occult nodal metastases among the patients who underwent END was $17 \%$ (38/226). The highest incidence of occult nodal metastases was with the oral cavity (66\%)." The Results section has similar phrasing: "Subgroup analysis showed that the highest incidences of occult nodal metastases were among the patients with oral cavity tumors $(66 \%, 25 / 38)$ and those with tumors of the major salivary gland $(24 \%, 9 / 38)$."

I fear that some readers would interpret this as stating that $66 \%$ of the oral cavity cancer patients had nodal metastases found at the time of END, when the correct statement is that $66 \%$ of the 38 patients with END and nodal metastases had oral cavity primaries. A separate paper about these patients, from the same group, makes it clear that the node positivity rate among oral cavity patients was much lower, at 22\%: "Subgroup analysis revealed that the highest incidence rates of occult nodal metastases were in patients with oral cavity tumors $(22 \%$; 25 of 116), and in those with cancer of the paranasal sinuses $\left(16 \%\right.$; 4/24)." ${ }^{2}$ The other paper's use of the term 'incidence' is more consistent with the textbook definition

\footnotetext{
(C) Society of Surgical Oncology 2020
}

First Received: 18 February 2020;

Published Online: 20 April 2020

M. F. Gensheimer, MD

e-mail: michael.gensheimer@gmail.com of incidence proportion ("the proportion of people who become cases during the time interval among those who were in the population at the start of the interval"). ${ }^{3}$ In this case, the population is patients with oral cavity adenoid cystic carcinoma who had END, and cases are the subset of that population with positive nodes found during END.

It could be helpful to correct the paper to make this clearer. If the paper is corrected, I would also consider modifying the abstract's statement that the analyzed group was " 270 patients who underwent neck dissection", as that number is from the other paper and includes patients who had therapeutic rather than elective neck dissection. ${ }^{2}$

DISCLOSURE Michael Gensheimer declares no conflicts of interest.

\section{REFERENCES}

1. Amit M, Na'ara S, Sharma $\mathrm{K}$, et al. Elective neck dissection in patients with head and neck adenoid cystic carcinoma: an international collaborative study. Ann Surg Oncol. 2015;22(4):1353-1359. https://doi.org/10.1245/s10434-014-41067.

2. Amit M, Binenbaum Y, Sharma K, et al. Incidence of cervical lymph node metastasis and its association with outcomes in patients with adenoid cystic carcinoma. An international collaborative study: neck metastasis in adenoid cystic carcinoma of the head and neck. Head Neck. 2015;37(7):1032-1037. https://doi.org/ 10.1002/hed.23711.

3. Ahrens W, Pigeot I (eds) Handbook of epidemiology. New York, NY: Springer 2014. https://doi.org/10.1007/978-0-387-09834-0.

Publisher's Note Springer Nature remains neutral with regard to jurisdictional claims in published maps and institutional affiliations. 